\title{
Journal of Bacteriology and

\section{Seroprevalence of Malaria Parasite Infection among Pregnant Women Attending Two Tertiary Health Facilities in Akure Ondo State Nigeria}

\section{Abe $\mathrm{AF}^{*}$ and Olusi TA}

Department of Biology, Federal University of Technology, Akure Ondo State, Nigeria

"Corresponding author: Abe AF, Department of Biology, Federal University of Technology, Akure Ondo State, Nigeria, Tel: +2348062592076; E-mail: foluksboby@yahoo.com

Rec date: May 08, 2014; Acc date: June 28, 2014; Pub date: June 30, 2014

Copyright: (C) 2014 Abe AF, et al. This is an open-access article distributed under the terms of the Creative Commons Attribution License, which permits unrestricted use, distribution, and reproduction in any medium, provided the original author and source are credited.

\begin{abstract}
The sequel outcomes and increased rates of maternal morbidity are partly consequences of the prevalence of malaria infections in pregnant women. This study was designed to investigate the prevalence of malaria parasite infection in pregnant mothers in State Specialist Hospital Akure. A total of 616 pregnant women aged 15-46 years who attended the major referral health facility for routine ante-natal purposes between February and April, 2012 were included in this exercise. Giemsa stained thick blood smears of the patients were examined for the presence of asexual stages of Plasmodium parasite. The Packed Celled Volume (PCV), genotype and blood group of the mothers were also determined using the haematocrit, electrophoresis and agglutination methods respectively. Descriptive statistics was used to determine the percentage of infections. Chi-square analysis was used to compare maternal data. Statistical comparison of malaria parasite and PCV was significant $p<0.05$, this probably shows that malaria infection is responsible for the anaemia in pregnant women in this study. The relationship between malaria parasite and genotype was not significant $(p>0.05)$ indicating that genotype of mothers in this present study have no influence in the distribution and prevalence of malaria. Out of 616 pregnant women examined, 597 (96.92\%) had malaria parasite infection while $19(3.08 \%)$ were not infected. The total prevalence rate $96.92 \%$ observed in the sampled population examined was very high though majority were infected at low parasitaemia is indicative of the endemicity of the disease in Akure metropolis. The difference in the mean PCV of malaria infected and non-infected mothers coupled with the high rate of malaria infection suggested the involvement of malaria in maternal anaemia.
\end{abstract}

Keywords: Epidemiology; malaria parasite Plasmodium falciparum; pregnant women; Packed celled volume

\section{Introduction}

Malaria has always been the subject of research for medical practitioners from time immemorial. Pregnant women, children, and immune compromised individuals have the highest morbidity and mortality, and Africa bears the heaviest burden of malaria infection. WHO [1] reported that pregnant women and the unborn children are vulnerable to malaria, which is a major cause of perinatal mortality, low birth weight and maternal anaemia. Malaria in pregnancy is a significant health problem in Nigeria and it thus requires systematic studies. Antecedent studies have recoded various rates of malaria prevalence among pregnant women. These include $21 \%$ among the pregnant women in South West Nigeria, $72 \%$ of 250 women also recorded order of high rate of anaemia, clinical malaria and placental burden among 300 women were examined in Ghana $[2,3]$.

The primary aim of this research work is to determine seroprevalence of malaria parasite infection among pregnant women in Akure Ondo State, Nigeria. This region is of special interest because of the free health care given to pregnant women during antenatal.

\section{Materials and Methods}

Akure the capital of Ondo State of South Western Nigeria is made up of 18 Local Government Areas. 616 pregnant women, who came from different Local Government Areas of Ondo State for routine antenatal visits at the State Specialist Hospital Akure between February and April, 2012, were randomly selected for this study. Venous blood was collected from the women where age ranged between 15-46 years. Thick blood films prepared on slides were stained following the method of Cheesbrough [4]. Haemoglobin Genotype, Blood Group and Packed Cell Volume of the patients were determined as previously described by Cheesbrough [4].

\section{Results}

\section{Prevalence of malaria parasitaemia in the different age groups}

The prevalence of malaria infection was calculated by comparing the number of individuals positive for malaria by Giemsa stained thick blood smears test with the total number examined. The population was grouped into seven age categories, and for each age group of pregnant mothers, the number positive and the infection rates are shown in Table 1 and 2.

Generally, a total of 597 pregnant women representing $96.92 \%$ of those tested had malaria infection apparently indicating that infection was generally very high in the sampled population. Women aged 15-19 and those 40 years and above were all infected with malaria, the rate of infection increase steadily through the age groups starting from aged 20-24 with $95.92 \%$ up to aged $35-39$ years with $99.04 \%$. The statistical relationship between malaria parasite and age of women was not significant $\left(\mathrm{X}^{2}=1.908 \mathrm{E} 2^{\mathrm{a}}, \mathrm{p}=0.965\right)$ (Table 3$)$. The differences in the distribution of Malaria parasiteamia across the categories of age was not significant ( $>0.05)$ (Table 4). 


\section{Characterization of malaria parasite density in relation to age of positive pregnant Women}

The density of malaria parasite in the different age groups of the 597 infected pregnant women was categorized as follows: $(+)$ low, $(++)$ moderate and $(+++)$ high parasiteamia. Result indicated that malaria with very high parasiteamia was found only in pregnant women aged 30-34 (0.17\%), moderate parasiteamia was found in mothers aged 15-39 (6.7\%) while the older ages were not infected and low parasiteamia was found in all the age groups (93.17\%) (Table 2).

\section{Relationship between PCV and malaria infection in pregnant women}

The Packed Cell Volume of the women included in this survey was studied in order to determine the effect of malaria on PCV among the women. On the basis of PCV women were also categorized -into two as shown in Table 5 . Women having $\mathrm{PCV}<30 \%$ were all positive to malaria (47); those infected and having PCV $\geq 30 \%$ were 550 and 19 women having PCV $\geq 30 \%$ were free from the infection. Results suggest that uninfected mothers had normal PCV while $7.87 \%$ of the infected women had low PCV and majority of the infected mothers (92.13\%) also have normal PCV, this is probably because of their low level of parasitaemia. The chi-square test on the effect of malaria parasite on the PCV of pregnant women was significant $\left(\mathrm{X}^{2}=1.406 \mathrm{E}^{\mathrm{a}}\right.$, $\mathrm{p}=0.00$ ) (Table 6).

\section{Results of prevalence of malaria infection among pregnant women with different genotype}

Out of the six hundred and sixteen pregnant women examined, result indicated that malaria infection is higher among mothers having heamoglobin genotype AA 445(97.16\%), followed by those with genotype AS 145(96.03\%), while six of the women with genotype AC and one with genotype SS, had malaria parasites (Table 7). Attempts were made to classify the infected mothers into low, moderate and high based on their parasitemia. The majority (556) of mothers had low parasitaemia, 40 women had moderate parasitaemia and only an individual had high parasiteamia. Statistical comparism of Malaria parasite and Genotype show was not significant $\left(X^{2}=77.917^{\mathrm{a}}, \mathrm{p}=0.996\right)$ (Table 8). Based on the separation of means the differences in the distribution of malaria infection across the different genotype were also not significant ( $p>0.05)$ (Table 9).

\section{The Prevalence of malaria infection in relation to blood group of pregnant women}

The blood grouping of the pregnant women surveyed were determined for the purpose of investigating the effect of blood grouping on malaria infection in the sampled population. Results obtained are summarized in Table 10. 138 of the pregnant women belonged to blood group A, 80 had blood group B, 12 belonged to blood group $\mathrm{AB}$ and 386 women had blood group $\mathrm{O}$. Mothers with blood group $\mathrm{AB}$ were all infected and had the highest prevalence of $100 \%$, followed by 79 of those with blood group B were infected (98.75\%), 373 of blood group O mothers were infected with $96.63 \%$ and 133 of the women with blood group A were infected with $96.38 \%$. The difference in the distribution of malaria parasites across the blood groups of mothers based on the separation of means was not significant $(p>0.05)$ (Table 9)

\begin{tabular}{|l|l|l|l|}
\hline \multicolumn{2}{|l|}{ Age group (Years) No examined } & No positive & Percentage positive \\
\hline $15-19$ & 13 & 13 & 100 \\
\hline $20-24$ & 49 & 47 & 95.92 \\
\hline $25-29$ & 211 & 203 & 96.21 \\
\hline $30-34$ & 222 & 214 & 96.39 \\
\hline $35-39$ & 104 & 103 & 99.04 \\
\hline $40-44$ & 14 & 14 & 100 \\
\hline$\geq 45$ & 3 & 3 & 100 \\
\hline Total & 616 & 597 & 96.92 \\
\hline
\end{tabular}

Table 1: The Prevalence of Malaria parasite among the different Age groups of Pregnant Women

\begin{tabular}{|l|l|l|l|}
\hline \multirow{2}{*}{ Age group (Years) } & \multicolumn{4}{|l|}{ Malaria parasite density } \\
\cline { 2 - 4 } & $\begin{array}{l}\text { Low } \\
(+)\end{array}$ & $\begin{array}{l}\text { Moderate } \\
(++)\end{array}$ & $\begin{array}{l}\text { High } \\
(+++)\end{array}$ \\
\hline $15-19$ & 12 & 1 & 0 \\
\hline $20-24$ & 42 & 5 & 0 \\
\hline $25-29$ & 187 & 16 & 0 \\
\hline $30-34$ & 201 & 12 & 1 \\
\hline $35-39$ & 97 & 6 & 0 \\
\hline $40-44$ & 14 & 0 & 0 \\
\hline$\geq 45$ & 3 & 0 & 0 \\
\hline Total & $556(93.17 \%)$ & $40(6.7 \%)$ & $1(0.17 \%)$ \\
\hline
\end{tabular}

Table 2: Characterization of malaria parasite density in relation to age of Positive Pregnant women. Age long medically accepted mode of classification of malaria parasite density in patients

\begin{tabular}{|l|l|l|l|}
\hline & Value & Df & Asymp. Sig. (2-sided) \\
\hline Pearson Chi-Square & $1.908 \mathrm{E} 2 \mathrm{a}$ & 228 & .965 \\
\hline Likelihood Ratio & 140.683 & 228 & 1.000 \\
\hline Linear-by-Linear Association & .128 & 1 & .720 \\
\hline
\end{tabular}


Citation: Abe AF, Olusi TA (2014) Seroprevalence of Malaria Parasite Infection among Pregnant Women Attending Two Tertiary Health Facilities in Akure Ondo State Nigeria. J Bacteriol Parasitol 5: 1000194. doi:10.4172/2155-9597.1000194

Page 3 of 6

$\mathrm{N}$ of Valid Cases 597

Table 3: Chi-square test between Malaria parasite and Age. a. 240 cells (87.9\%) have expected count less than 5. The minimum expected count is . 01

\begin{tabular}{|l|l|}
\hline Age group (years) & Malaria parasite mean/standard error \\
\hline $15-19$ & $9.92 \pm 3.25^{\mathrm{a}}$ \\
\hline $20-24$ & $7.29 \pm 1.19^{\mathrm{a}}$ \\
\hline $25-29$ & $7.87 \pm 0.67^{\mathrm{a}}$ \\
\hline $30-34$ & $8.26 \pm 0.78^{\mathrm{a}}$ \\
\hline $35-39$ & $7.82 \pm 0.92^{\mathrm{a}}$ \\
\hline $40-44$ & $6.07 \pm 0.58^{\mathrm{a}}$ \\
\hline$\geq 45$ & $8.33 \pm 0.88^{\mathrm{a}}$ \\
\hline Sig & 0.418 \\
\hline
\end{tabular}

Table 4: Comparison of mean values of malaria parasite in relation to age groups of pregnant women. Mean followed by the same letter in a column are not significantly different $(\mathrm{p}>0.05)$ from each other using New Duncan Multiple Range Test

\begin{tabular}{|l|l|l|l|}
\hline \multirow{2}{*}{ Malaria status } & \multicolumn{2}{|c|}{ PCV } & \multirow{2}{*}{ Total } \\
\cline { 2 - 3 } & $<30$ & $\geq 30$ & \\
\hline No (\%) positive & $47(7.87 \%)$ & $550(92.13 \%)$ & 597 \\
\hline No (\%) negative & - & $19(100 \%)$ & 19 \\
\hline
\end{tabular}

Table 5: Relationship between PCV and malaria infection in pregnant women. Key: PCV $<30 \%$ - Low Packed Cell Volume, PCV $\geq 30 \%$ - Normal Packed Cell Volume

\begin{tabular}{|l|l|l|l|}
\hline & Value & Df & Asymp. Sig. (2-sided) \\
\hline Pearson Chi-Square & $1.406 \mathrm{E3}^{\mathrm{a}}$ & 1026 & .000 \\
\hline Likelihood Ratio & 402.218 & 1026 & 1.000 \\
\hline Linear-by-Linear Association & .114 & 1 & .736 \\
\hline N of Valid Cases & 597 & & \\
\hline
\end{tabular}

Table 6: Chi-square test between Malaria parasite and PCV. a. 1058 cells (96.9\%) have expected count less than 5. The minimum expected count is .00

\begin{tabular}{|c|c|c|c|c|c|c|}
\hline \multirow[t]{2}{*}{ Genotype } & \multirow[t]{2}{*}{ Number examined } & \multicolumn{3}{|c|}{ Malaria parasite density } & \multirow[t]{2}{*}{ Number Positive } & \multirow[t]{2}{*}{ Percentage Positive } \\
\hline & & Low & Moderate & High & & \\
\hline AA & 458 & 419 & 26 & - & 445 & 97.16 \\
\hline AS & 151 & 130 & 14 & 1 & 145 & 96.03 \\
\hline$A C$ & 6 & 6 & - & - & 6 & 100 \\
\hline SS & 1 & 1 & - & - & 1 & 100 \\
\hline
\end{tabular}




\begin{tabular}{|l|l|l|l|l|l|l|}
\hline Total & 616 & 556 & 40 & 1 & 597 & 96.92 \\
\hline
\end{tabular}

Table 7: Result of Prevalence of Malaria infection among pregnant women with different Genotype

\begin{tabular}{|l|l|l|l|}
\hline & Value & Df & Asymp. Sig. (2-sided) \\
\hline Pearson Chi-Square & $77.917^{\mathrm{a}}$ & 114 & .996 \\
\hline Likelihood Ratio & 69.191 & 114 & 1.000 \\
\hline Linear-by-Linear Association & 1.498 & 1 & .221 \\
\hline N of Valid Cases & 593 & & \\
\hline
\end{tabular}

Table 8: Chi-Square Tests between Malaria parasite and Genotype a. 137 cells (87.8\%) have expected count less than 5. The minimum expected count is .00

\begin{tabular}{|l|l|l|l|}
\hline Genotype & Malaria parasite mean/standard error & Blood group & Malaria parasite mean/standard error \\
\hline AA & $7.60 \pm 0.41^{\mathrm{a}}$ & A & $9.62 \pm 1.15^{\mathrm{a}}$ \\
\hline AS & $9.17 \pm 1.14^{\mathrm{a}}$ & B & $8.80 \pm 1.52^{\mathrm{a}}$ \\
\hline AC & $5.33 \pm 1.09^{\mathrm{a}}$ & AB & $6.83 \pm 0.75^{\mathrm{a}}$ \\
\hline SS & $5.00 \pm 0.00^{\mathrm{a}}$ & O & $7.23 \pm 0.41^{\mathrm{a}}$ \\
\hline Sig & 0.309 & Sig & 0.288 \\
\hline
\end{tabular}

Table 9: Comparison of mean values of Parameters with malaria parasite of pregnant women. Mean followed by the same letter in a column are not significantly different $(p>0.05)$ from each other using New Duncan Multiple Range Test

\begin{tabular}{|l|l|l|l|}
\hline Blood group & No examined & No positive & Percentage positive \\
\hline A & 138 & 133 & 96.38 \\
\hline B & 80 & 79 & 98.75 \\
\hline AB & 12 & 12 & 100 \\
\hline O & 386 & 373 & 96.63 \\
\hline Total & 616 & 597 & 96.92 \\
\hline
\end{tabular}

The high infection rate observed among women aged 15-19 and 40 years and above was probably an indication that immunity to malaria infection was low as a result of primigravidae (first pregnancy) state of the women that consequently make them more susceptible to malaria infection than others who are multigravidae [5]. Oforie [3] explained that Immunity to malaria infection diminishes significantly in pregnancy particularly in primigravidae. In first and second pregnancies women were especially vulnerable to malaria infection. Mcgregor [8] identify the factors responsible for susceptibility of primigravidae to malaria to be inhibition of type 1 cytokine responses (interferon, interleukin 2 and 12 and TNF). Brabin, [9] also found that

Table 10: Prevalence of Malaria infection in Relation to Blood groups of pregnant women the primigravidae were more susceptible to malaria infection than the multigravidae. According to Opare Addo [10] the primigravidae alongside those women in their second pregnancy were more vulnerable to malaria parasitemia. Although their findings were in contrast to those of McGregor [11] who reported a decline in malaria prevalence as age increase and that with improved host immunity susceptibility was reduced in later years. Statistical analysis, revealed that ages of pregnant women have no influence on the distribution of malaria parasite since the differences in the prevalence of infection among the various age group was not significant.

The result of this study revealed that pregnant women in the different age groups were infected at different parasiteamia densities. The low parasitaemia observed in all the age group of pregnant women could be the reason why they did not come down with malaria despite being infected. This indicated that pregnant women could be carriers of malaria parasites without showing any symptoms to the infection. The high parasitaemia observed in aged 30-34 could be as a result of co-infection with HIV which has impaired the immunity of the 
mother. Marielle reported high prevalence rate in pregnant women in Gabon, with higher infection in primigravidae than multigravidae in woman within age group 36-39 years [12].

Malaria parasitemia often causes anaemia, increased uterine activity and low birth weight, among others [13,14]. According to Brabin [15] at pregnancy immunity has been altered, hence, with malaria $70-80 \%$ of pregnant women in malarious area are susceptible to anaemia. The PCV of pregnant women were grouped based on the definition of anaemia in pregnancy in our environment which is PCV of less than $30 \%$ [16]. The prevalence of malaria parasites in this study was generally high, the mean PCV $33.89 \pm 3.88$ among malaria infected mothers was lower than mean PCV $34.58 \pm 3.06$ of those without malaria parasite which can be suggestive of anaemia in pregnancy. This finding can be compare with other studies which recorded high prevalence rates observed high prevalence $(76.5 \%)$ of anaemia in pregnancy in Abeokuta [17-20]. Analysis from this research probably showed that malaria infection is responsible for the anaemia in pregnant women in this study. The chi-square test indicates that the effect of malaria on PCV of women were significant ( $\mathrm{p}=0.000)$.

Invasion of red blood cells (erythrocyte) by $P$. falciparum leads to very high infection rate. Anaemia in falciparum malaria is due mainly to the destruction of parasitized red cells. Uninvaded red cells are lysed during malaria attack; both parasitized cells and unparasitized cells are phagocytosed and destroyed in large numbers by the cells of the spleen and liver. It leads to folic acid deficiency and anaemia develops as loss of red blood cells may be extensive and rapid. The production of red cells in the bone marrow is also reduced and there is a slow reticulocyte response. An immune destruction of non-parasitized cells also occurs. According to Ogbodo [21] increased parasite density ultimately leads to increase in red cell breakdown and consequently anaemia. Desai [22] also reported that women with severe anaemia are at higher risk for morbidities such as congestive heart failure, fetal demise, and mortality associated with hemorrhage at the time of delivery.

Findings from this present study support the fact that sickle cell trait carriers have lower parasites densities and are more protected against death from severe malaria and the development of hyper reactive malaria splenomagaly compare with heamoglobin genotype $\mathrm{AA}$ and AS individuals [4]. Infection was higher in mothers having heamoglobin genotype AA which is usually reasonable because of their genetic constitution in that after the invasion by Plasmodium, haemoglobin genotype AA can survive till the end of the developmental cycle (erythrocytic cycle) of Plasmodium and the body identifies the haemoglobin genotype AA as normal red blood cell in nature which will not be destroyed by the spleen, thereby enabling the parasite to gain ground to multiply and thrive in the infected individual. Unlike the haemoglobin genotype AS (abnormal sickle) red blood cell in nature do not survive till the end of the erythrocytic cycle, because the body identify the sickle shaped cell as abnormal and are destroyed by the spleen. Therefore, parasitemia can be put under check in the haemoglobin genotype AS than the haemoglobin genotype AA especially when the immune system is high. This fact could be responsible for the high parasitaemia in pregnant woman having haemoglobin genotype AS because the mother was co-infected with both HIV and malaria parasite which is double tragedy. The effects of HIV antibodies in the pregnant woman could have weaken her immunity to malaria infection. The relationship between malaria and genotype of mothers showed no significant difference and this indicates that genotype has no influence on the epidemiology of malaria among the pregnant women in this present study.

In regions highly endemic for $P$. falciparum malaria red cell polymorphisms that confer resistance to malaria are widespread, and tolerance to malaria based on inherited factors is well described [23]. It was observed from this research work that pregnant women having blood group $\mathrm{AB}$ had the highest malaria prevalence followed by those with blood group B while women with blood group A recorded the lowest prevalence. Statistical relationship of malaria infection among pregnant women of different blood grouping was not significant despite the high prevalence rate of infection among the women. This could probably because majority of the pregnant women had low parasitaemia. However blood groups of women in this study was not the determinant factor for the prevalence of malaria infection.

\section{Conclusion}

Malaria has become one of the most challenging infectious diseases to eradicate in Africa.

\section{Recommendation}

It is therefore recommended that all pregnant women attending antenatal clinic in Ondo State Specialist Hospital be tested for malaria parasite every month in order to detect early in case of any symptomatic or asymptomatic malaria infection so as to be treated appropriately and to prevent further morbidity and mortality associated with malaria.

There is need for Government to provide Intermittent Preventive Treatment for all pregnant women with effective anti-malarial drug during routine antenatal clinic visits. Mosquito treated net should be made available free for the pregnant women. Training on how to use the net must be given as this will decrease the exposure to infective mosquito bites.

More impressive Public announcement and awareness should be made to the pregnant women in the public to register early and attend good antenatal clinic for proper handling of their health and pregnancy from malaria

\section{Acknowledgement}

The authors are grateful to the management of Ondo State Specialist Hospital for granting us audience to collect the sample for this research work. We also appreciate Mr. Lawrence Ogundoju of Federal University of Technology, Akure health centre where the laboratory analyses of the samples gotten were carried out.

\section{References}

1. World Health Organization (1991) Basic Laboratory Methods in Medical Parasitology. World Health Organization Geneva.

2. Adefioye OA, Adeyeba OA, Hassan WO, Oyeniran OA(2007) Prevalence of Malaria Parasite Infection among Pregnant Women in Osogbo,Southwest, Nigerian. American-Eurasian Journal of Scientific Research 2: 43-45.

3. Ofori M, Ansah E, Agyepong I, Ofori-Adjei D, Hviid L, et al. (2009) Pregnancy-associated malaria in a rural community of ghana. Ghana Med J 43: 13-18. 
Citation: Abe AF, Olusi TA (2014) Seroprevalence of Malaria Parasite Infection among Pregnant Women Attending Two Tertiary Health Facilities in Akure Ondo State Nigeria. J Bacteriol Parasitol 5: 1000194. doi:10.4172/2155-9597.1000194

Page 6 of 6

4. Cheesbrough M (2005) District Laboratory Practice in Tropical Countries. (2nd Edtn) Cambridge University Press, United Kingdom.pp. 244-251.

5. Martra N, Joshi M, Haziam M (1993) Maternal manifestation of malaria in pregnancy. A review. Indian J Matern Child Health 4: 98-101.

6. Falade CO, Olayemi O, Dada-Adegbola HO, Aimakhu CO, Ademowo OG, et al. (2008) Prevalence of malaria at booking among antenata clients in a secondary health care facility in Ibadan, Nigeria. Afr J Reprod Health 12: 141-152.

7. Chukwura EI, Okpala EE, Ani I (2003) The prevalence of malaria parasites in pregnant women and other patients in Awka Urban, Anambra State. J biomedical Invest 1: 48-52.

8. McGregor IA (1984) Epidemiology, malaria and pregnancy. Am J Trop Med Hyg 33: 517-525.

9. Brabin B J (1991) The risks and severity of malaria in pregnant women In: Applied field research in malaria. Report no. 1. Geneva WHO 1-34.

10. Opare Addo HS, Odoi AT (2002) Malaria in pregnancy. (Kwawukueme EY, Emuveyan EE, editors) Comprehensive Obstetrics in the tropics. (1st edtn) Accra, Ghanna: Asante and Hittscher Printing Press Publishers 250-260.

11. McGregor IA, Wilson ME, Billewiez WZ (1983) Malaria infection of the placental in the Gambia West Africa. Its incidence and relationship to still birth weight and placental weight. Trans R Soc Trop Med Hyg 77:232-224

12. Marielle KBA, Denisa EIC, Modeste MM, K Eric, Pierre BM, et al. (2003) Prevalence of Plasmodium falciparum Infection in Pregnant women in Gabon. Malaria Journal 2: 1-17.

13. Massawe SN, Urassa EN, Mmari M, Ronquist G, Lindmark G, et al. (1999) The complexity of pregnancy anemia in Dar-es-Salaam. Gynecol Obstet Invest 47: 76-82.
14. Egwunyenga OA1, Ajayi JA, Popova-Duhlinska DD, Nmorsi OP (1996) Malaria infection of the cord and birthweights in Nigerians. Cent Afr J Med 42: 265-268.

15. Brabin BJ (1983) An analysis of malaria in pregnancy in Africa. Bull World Health Organ 61: 1005-1016.

16. Ogunbode O (1984) Management of anaemia in pregnancy. Niger Med Pract 8: 105-107.

17. Bouyou-Akotet MK, Ionete-Collard DE, Mabika-Manfoumbi M, Kendjo E, Matsiegui PB, et al. (2003) Prevalence of Plasmodium falciparum infection in pregnant women in Gabon. Malar J 2: 18.

18. Nwagha UI, Ugwu VO, Nwagha TU, Anyaehie BU (2009) Asymptomatic Plasmodium parasitaemia in pregnant Nigerian women: almost a decade after Roll Back Malaria. Trans R Soc Trop Med Hyg 103: 16-20.

19. Brabin BJ, Prinsen-Geerligs PD, Verhoeff FH, Fletcher KA, Chimsuku $\mathrm{LH}$, et al. (2004) Haematological profiles of the people of rural southern Malawi: an overview. Ann Trop Med Parasitol 98: 71-83.

20. Idowu OA, Mafiana CF, Dapo S (2006) Malaria among pregnant women in Abeokuta, Nigeria. Tanzan Health Res Bull 8: 28-31.

21. Ogbodo SO, Nwagha UI, Okaka AN, Ogenyi SC, Okoko RO, et al. (2009) Malaria parasitaemia among pregnant women in a rural community of eastern Nigeria; need for combined measures. Niger J Physiol Sci 24: 95-100.

22. Desai M, ter Kuile FO, Nosten F, McGready R, Asamoa K, et al. (2007) Epidemiology and burden of malaria in pregnancy. Lancet Infect Dis 7: 93-104.

23. Min-Oo G, Gros P (2005) Erythrocyte variants and the nature of their malaria protective effect. Cell Microbiol 7: 753-763. 